\title{
PESTICIDAL PLANTS IN AFRICAN AGRICULTURE: LOCAL USES AND GLOBAL PERSPECTIVES
}

\author{
Philip C. Stevenson and Steven R. Belmain from the Natural Resources Institute, University of Greenwich \\ provide an overview of progress in developing pesticidal plants in Africa and the further challenges and \\ opportunities faced to provide more agro-ecologically sustainable pest management
}

Keywords: botanical insecticide, pesticidal plants, biorational pest management

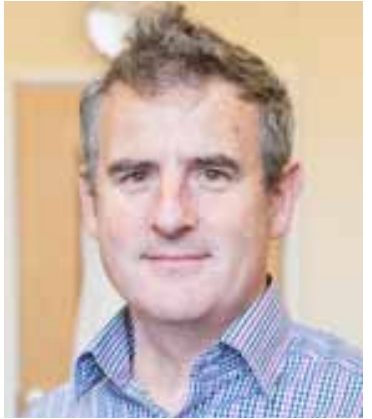

Philip Stevenson

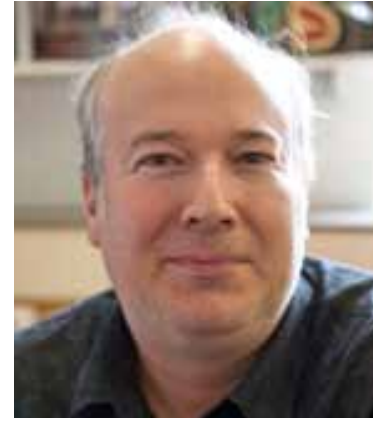

Steven Belmain

\section{Introduction}

In 2001 in this publication we drew attention to the wealth of potential in pesticidal plants in Africa. We reported from a regional focus on West Africa where we had been undertaking research identifying new plant sources of pesticides, verifying their efficacy and considering how we could apply our scientific knowledge to improving the way farmers used them (Belmain \& Stevenson 2001). Here, 15 years on, we consider how this research and development domain has changed, what are the success stories and priorities for Africa and where is this sector heading.

Plants cannot move so must defend themselves against herbivores where they stand. We occasionally encounter these defensive traits when we are stung by nettles or pricked by a cactus. However, most plants depend on non-physical chemical mechanisms of defence which are often subtle but highly effective survival strategies. Farmers across the world have for centuries exploited these biological activities and used plants that have particularly potent defence chemicals to control pests in stored food or in the field. In fact, the earliest commercial pesticides were of plant origin such as rotenone and nicotine (Ott 2006; Gerwick \& Sparks 2014) but the dawn of industrial organic chemistry provided a suite of highly effective pest control agents that left plant chemistry far behind. Yet as the negative environmental impacts of synthetic chemicals began to emerge in the 1960s and 70s, the pendulum swung back towards more natural pest management strategies during the 1980 s and 90s. Scientists were again full of optimism that plants might provide the next generation of effective but environmentally benign pesticides. A huge amount of time and resource was invested to study plants for their potential as pesticides. The better studied was the Neem tree (Azadirachta indica) which produces tetratnortriterpenoid feeding repellents and development inhibitors including azadirachtin A and several analogues (Koul 2008). While some plant products have had limited commercial success globally these have largely been restricted to Neem (triterpenoids), Derris (rotenoids), Pyrethrum (pyrethrins) and various mixtures of essential oil products (e.g. 1, 8 cineole, $\alpha$-pinene, verbenone) (Isman 2008). The optimism of the 80s and 90s unfortunately did not deliver a revolution in more natural pest control products, and a recent assessment of biological pesticides of any kind suggests they constitute less than $1 \%$ of all pest control products, with pesticidal plants being a small fraction of this (Isman 2006; Isman \& Grieneisen 2013).

\section{Challenges and opportunities}

Policy changes in Europe and elsewhere requiring more thorough safety data and maximum residue limits for synthetic pesticides may have changed the commercial scope for plant based pesticides. Some countries such as China, India and Brazil have created favourable regulatory frameworks and have subsequently seen considerable growth in the number of registered commercial plant based pesticides. Across the African continent there remains a strong heritage and ongoing use of plants as pesticides, particularly in small holder agriculture. Also, until relatively recently, East Africa was the main global provider of crude pyrethrum. So although there is great potential for natural pesticide development in Africa, many questions remain on whether African governments, policy makers and scientists can create the enabling regulatory environments required to help facilitate entrepreneurs wanting to develop local practices into sustainable value chains for commercialised pest control products.

As our earlier article highlighted, smallholder farming is where pesticidal plants still have the most to offer. Many small holders live in remote locations where access to commercial products is unreliable, products are often adulterated, out dated, poorly labelled and with many farmers still using globally banned or redundant substances. This of course overlooks the fact that pesticides, even if available, are often used incorrectly, sometimes at very high concentrations owing to illiteracy and poor training. Misuse of synthetics by small holder farmers is particularly hazardous to users who do little to protect themselves (Figure 1) and exacerbates wellknown environmental hazards and consumer poisoning risks through poorly informed practice. Plants on the other hand 


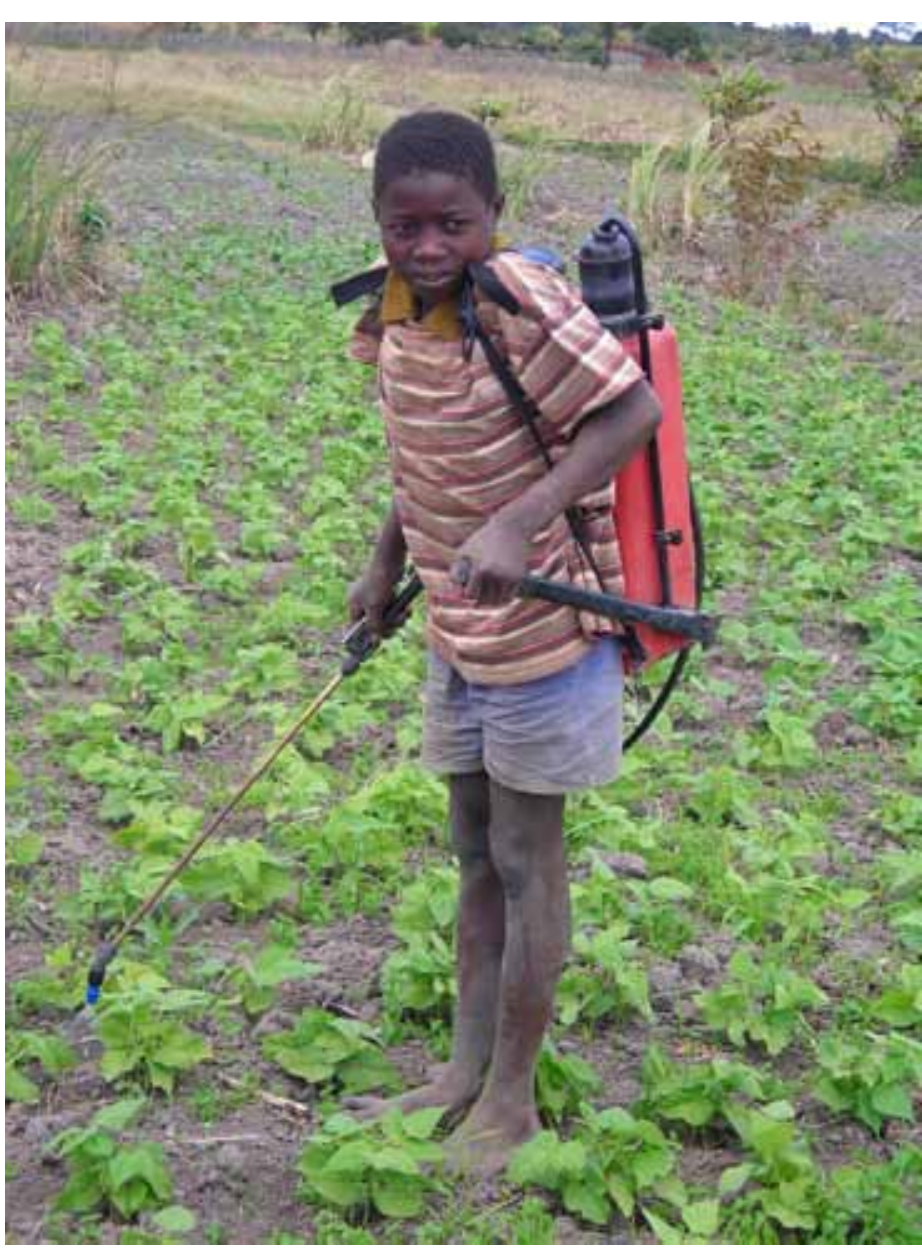

Figure I. Human health prevention and safety are often low priorities in Africa. Pesticide exposure for farmers and consumers is a serious risk to health, and finding new environmentally benign options should be a priority.

are a known quantity to smallholders, and while typically less effective than synthetic pesticides, that can provide some efficacy which is often as good as commercial synthetics, and as our recent work shows, have lower impacts on important ecosystem service providers such as beneficial insects.

It is worth quickly clarifying what we consider to be pesticidal plants. These are plant materials that are unprocessed and require little or no formulation or additives beyond perhaps adding a small amount of soap as a surfactant. This differs from botanical insecticides which are of plant origin but similar to synthetic insecticides in that they are refined and formulated with additives to help stabilise and improve efficacy and sold as a ready-made product. By this definition pesticidal plants are not perfect and there are several hurdles that need to be overcome to make them successful with consistent efficacy. To begin with, plants are a natural product and, therefore, highly variable in chemical content that can be affected by origin and source or at different times of the year or under different ecological pressures which influence their chemistry and thus efficacy. Other challenges such as the environmental impacts of collecting plants from the wild must be understood. The availability of plant materials is an increasing challenge due to habitat degradation and climate change affecting plant species abundance and habitat prevalence. If our experience running field trials in Ghana in the late 1990s and early 2000s taught us anything it was that large amounts of plant material are required and availability of some species is a limiting factor. In fact, encouraging the use of some species could be an environmental disaster by simply encouraging large scale wild harvest. Further challenges have been identified through surveys undertaken with farmers in Malawi where many recounted ineffective plant materials that had been recommended to them by an international agroforestry institute, emphasizing an underlying uncertainty among farmers on using pesticidal plants. Our work has addressed each of these factors and has provided guidance on how we can use pesticidal plants more effectively and deliver consistent results for farmers. We believe that if these approaches are adopted more widely then the use of pesticidal plant materials in pest control could become a much more important and valuable component of pest management in Africa. Much depends upon our ability to identify the best provenances and this is dependent on chemical knowledge.

A great example of this arose during research in Malawi where some farmers reported that the Tephrosia vogelii they were using simply did not work as they were told it would. Tephrosia is a genus of leguminous shrubs many of which are reported to produce rotenoids, one of which is rotenone, a well-known bioactive compound with potent insecticidal properties among other activities. In our work to find out what the active compounds in this particular species were, we uncovered several important problems that had been overlooked in the use and uptake of pesticidal plants. Confusion had arisen during outreach activities in Malawi from an agroforestry project that had propagated and promoted what was believed to be a related species, Tephrosia candida, because it fixed nitrogen and could be ploughed into fallow land as a green mulch (Figure 2). Its pesticidal properties were promoted as an additional benefit. However, approaching the problem systematically by first verifying the plant material with the Royal Botanic Gardens Kew Herbarium, we established straight away that this second species was not T. cand$i d a$ at all but was actually T. vogelii. However, further chemical work revealed that the chemistry of this provenance of the species was different to other material we had collected. In fact, the rotenoid biosynthetic pathway appeared to be absent entirely from one group of plants from this species in Malawi and the difference was so stark as to lead us to recognize two chemotypes, one which was biologically active and another which was inactive (Stevenson et al. 2012; Belmain et al. 2012). Around $25 \%$ of the plant material growing and being used in Malawi was of the inactive chemotype. Not only did this explain why farmers were not achieving the pesticidal benefits, but this enabled us to establish a mechanism for selecting the correct chemotypes for propagation and distribution through outreach networks.

Seasonal variation in chemical expression might influence how or when farmers harvest plant materials. Having identified the bioactive chemicals meant we were able to determine the best time of year to harvest T. vogelii to obtain the highest yields of active ingredient (Belmain et al. 2012). An additional useful piece of information that arose from this work on rotenoids was pertinent to farmers who made extracts to apply in a sprayer. Rotenoids are largely water insoluble so where farmers extracted in water the efficiency of extraction was 


\section{PESTICIDAL PLANTS IN AFRICAN AGRICULTURE}

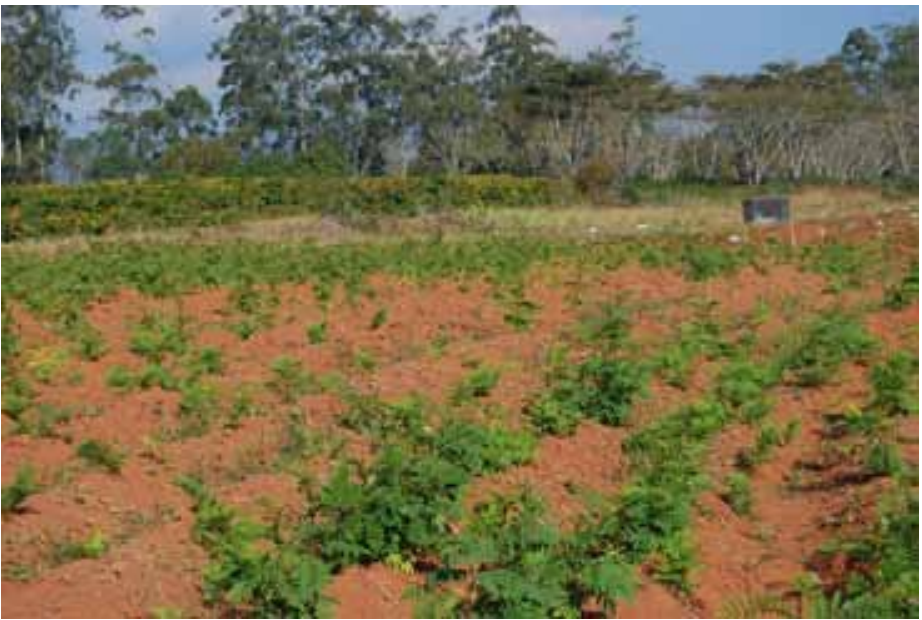

Figure 2. Tephrosia vogelii offers easily propagated pesticidal plant material that can also improve soil quality in depleted land.

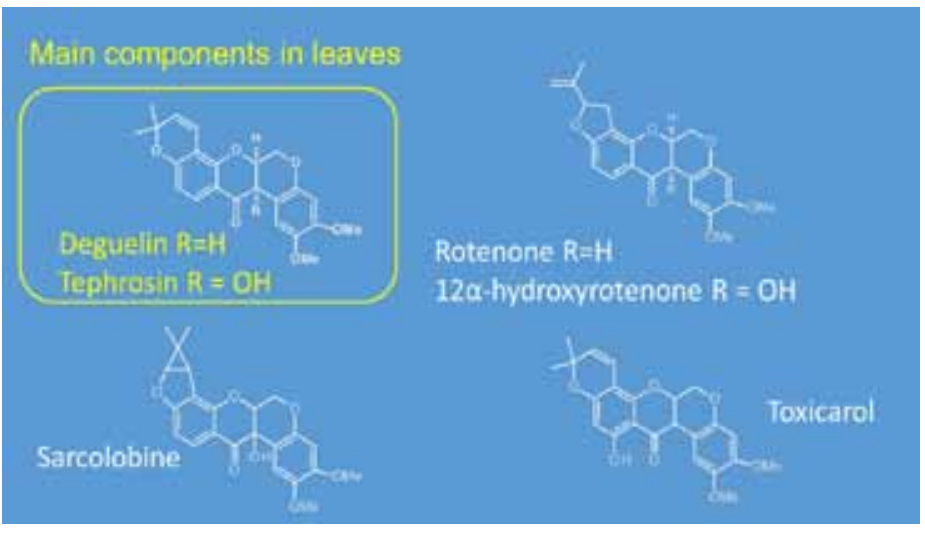

Figure 3. The main rotenoids in Tephrosia vogelii are deguelin and tephrosin with the former showing the highest biological activity.

poor and the bioactivity of subsequent extracts low (Figure 3). Comparative analysis of methanol and dilute liquid soap extracts of T. vogelii indicated that water with a bit of soap helped the extraction of non-polar rotenoid compounds, although clearly not as effective as the organic solvent. Furthermore, by incorporating soap in the extract meant the final product already contained a surfactant agent that could help improve application to field crops.

\section{Ecological compatibility of pesticidal plants}

More recently our work has focused on understanding the ecosystem impacts and compatibility of pesticidal plants within global efforts for agro-ecological intensification and sustainable agriculture. Some species such as the South American Ageratum conyzoides (goat weed) is now ubiquitous across disturbed and cultivated land in Africa and is also pesticidal. In collaboration with Charles Sturt University in Australia and Kumasi Polytechnic, Ghana we evaluated several different common Ghanaian plants including goat weed for the insecticidal efficacy against the diamond backed moth (Plutella xylostella) and cabbage aphid (Brevicoryne brassica) on cabbage. All the plant pesticides controlled both pests and some, including goat weed, were as effective as the commercial synthetic Attack (permethrin + pirimiphos-methyl). But perhaps most significantly the impacts of the pesticidal plant treatments on the third trophic level, e.g., spiders, ladybirds and hoverflies, were significantly lower for the plant extracts (Amoabeng et al. 2013). We have also shown similarly effective pest control and even better bean yields associated with reduced impacts on beneficial insects in research in Tanzania using a group of native plants and exotic weeds against insects on the common bean (Phaseolus vulgaris), suggesting that there may be a pattern here (Mkenda et al. 2015). Many plant chemicals are UV labile so when exposed on plant surfaces may break down more rapidly. So while they have time to inflict some level of control on the pest, they are not persistent enough to level the same toxicity against the third trophic level as synthetics. Indeed our data suggest that the lower impact of the pesticidal plant treatments on the beneficial insects is exactly what allows farmers to achieve higher bean yields compared with synthetics because the plant based pest management approach allowed beneficial insects to thrive and contribute to the pest control.

Of course none of this matters if farmers are not making money. So much of our recent work has not only focussed on environmental benefits, but on field trials aimed at demonstrating yield and cost benefits, all of which are areas that are typically overlooked by scientists in this arena. In a comparison of the cost-to-benefit ratio, crude extracts of Ageratum conyzoides, Chromolaena odorata and Synedrella nodiflora were compared with the synthetic insecticide emamectin benzoate against insect pests of cabbage over two seasons for their economic return. Cost included material and labour with revenue derived from the marketable yield of cabbage. The cost of plant protection using the synthetic was always higher than the plant extracts. While the plant based materials differed markedly in levels of control and cost-benefits, some were comparable to that from conventional insecticide. Furthermore, the pesticidal plant treatments could be produced easily from locally available plant materials and are likely to be safer to use for smallholder farmers and consumers in developing countries (Amoabeng et al. 2014). Similarly, recent work in Tanzania on common beans showed that bean yield was highest when using water based extracts of Tephrosia vogelii or Tithonia diversifolia, even compared with the synthetic (Karate - lambda-cyhalothrin) which itself provided no better bean yield than treatment with Lippia javanica or Vernonia amygdalina (Mkenda et al. 2015). Due to the relative high cost of the synthetic compared to the labour costs of collecting and processing the plant materials, the economic return was substantially higher with the plant treatments $(\$ 5.50 / \mathrm{ha})$ than with the synthetic $(\$ 4.00 / \mathrm{ha})$. Indeed, due to lower input costs, the economic return of the untreated control was the same as using the synthetic, albeit the untreated control did have a significantly lower yield.

\section{Commercial potential and future prospects}

Growing demand for alternatives to pesticides that are not only effective but also have low risks to health and ecosystems is stimulating an increasing interest in plant based products in many parts of the world. Globally, the demand for natural pesticides is growing due to consumers who are increasingly demanding safe food, often organically produced. This 
is accompanied by changes in international trade regulations, particularly in Europe. Unfortunately these demands for natural pesticides are poorly served through existing regulatory frameworks that were designed for the registration of persistent synthetic single chemical technologies, where the burden of these approval systems is poorly suited to regulating complex mixtures of non-persistent natural chemicals. Some countries, notably India, China and Brazil, have led the way in policy changes that have enabled more widespread commercialisation and use of natural plant based products and botanical pesticides. In Africa wide-scale uptake of pesticidal plants remains limited despite its historic and global role in the production of pyrethrum. We reviewed the sector in Africa and found that the reasons were complex and related to a lack of data on efficacy and safety, inconsistent efficacy of plant products, the prohibitive cost of registration, and an inadequately developed conventional pesticides sector (Sola $e t$ al. 2014). Regulations and protocols for production, marketing and trade may benefit from further review if Africa is to capitalise on its strengths of existing widespread use of pesticidal plants at the small holder level and the many endemic plant species with confirmed pesticidal properties.

Besides regulatory hurdles related to pesticide products, Africa needs to do more to enhance sustainable management of its natural resources. Agricultural and urban expansion, over-grazing, deforestation, bush fires and climate change are conspiring together to degrade natural habitats where many indigenous plant species are increasingly rare. Capitalising on the ecosystem services that can be provided from wild plants being used as natural pesticides is threatened by current regulations that often provide little incentive to habitat protection as the ecosystem benefits are not well-recognised. With declining natural resources, pesticidal plants will increasingly need to be cultivated as crops, themselves, if they are to continue to be available to small holder farmers. Indeed, the commercialisation of pesticidal plants in Africa will need to look further at how to propagate pesticidal plant species in order to produce the huge quantities of plant material that would be required to produce these organic technologies at a commercial scale. The pyrethrum sector used to employ tens of thousands of small holder farmers across East Africa, particularly in Kenya. The Kenyan pyrethrum industry largely collapsed through poor policies and regulation, with other parts of the world (Australia, China) picking up the opportunity to produce a product in global demand. Africa has the opportunity to diversify its non-food agricultural production with many pesticidal species. This would not only provide many farmers with a good livelihood, but could help reduce reliance on the import of synthetic pesticides, which are often subsidised by African governments, and help develop African businesses involved in manufacturing pest management products as well as help export horticulture businesses looking to reduce residues on their produce sent to Europe and beyond. The challenges to realise these opportunities are not insurmountable and require good cooperation between African entrepreneurs and policy makers with some backstopping from the scientific community; as scientists, we are ready to help.

\section{Acknowledgements}

The authors gratefully acknowledge funding for their work from the McKnight Foundation supported project "Safe and effective pesticidal plants for agro-ecological intensification of legumes", and the European Union African-Caribbean-Pacific Science and Technology Programme "OPTIONs project" (FED/2013/329-272).

\section{References}

Amoabeng, B. W., Gurr, G. M., Gitau, C. W., Nicol, H. I., Munyakazi, L., \& Stevenson, P. C. (2013). Tri-trophic insecticidal effects of African plants against cabbage pests Ed N. Desneux. PloS one 8, e78651.

Amoabeng, B. W., Gurr, G. M., Gitau, C. W., \& Stevenson, P. C. (2014). Cost:benefit analysis of botanical insecticide use in cabbage: Implications for smallholder farmers in developing countries. Crop Protection 57, 71-76.

Belmain, S. R., Amoah, B. A., Nyirenda, S. P., Kamanula, J. F., \& Stevenson, P. C. (2012). Highly variable insect control efficacy of Tephrosia vogelii chemotypes. Journal of agricultural and food chemistry 60, 10055-10063.

Belmain, S. R., \& Stevenson, P. C. (2001). Ethnobotanicals in Ghana: Revising and modernising age-old farmer practice. Pesticide Outlook 6, 233-238.

Gerwick, B. C., \& Sparks, T. C. (2014). Natural products for pest control: An analysis of their role, value and future. Pest Management Science 70, 1169-1185.

Isman, M. B. (2006). Botanical insecticides, deterrents, and repellents in modern agriculture and an increasingly regulated world. Annual Review of Entomology 51, 45-66.

Isman, M. B. (2008). Botanical insecticides: For richer, for poorer. Pest Management Science 64, 8-11.

Isman, M. B., \& Grieneisen, M. L. (2013). Botanical insecticide research: many publications, limited useful data. Trends in plant science 19, 1-6.

Koul, O. (2008). Phytochemicals and Insect Control : an antifeedant approach. Critical Reviews in Plant Science 27, 24.

Mkenda, P., Mwanauta, R., Stevenson, P. C., Ndakidemi, P., Mtei, K., \& Belmain, S. R. (2015). Extracts from Field Margin Weeds Provide Economically Viable and Environmentally Benign Pest Control Compared to Synthetic Pesticides. Plos One 10, e0143530.

Ott, K. C. (2006). Rotenone. A Brief Review of its Chemistry, Environmental Fate, and the Toxicity of Rotenone Formulations. Available at: http://www.newmexicotu.org/Rotenone summary. pdf

Sola, P., Mvumi, B. M., Ogendo, J. O., Mponda, O., Kamanula, J. F., Nyirenda, S. P., Belmain, S. R., \& Stevenson, P. C. (2014). Botanical pesticide production, trade and regulatory mechanisms in sub-Saharan Africa: making a case for plant-based pesticidal products. Food Security 6, 369-384.

Stevenson, P. C., Kite, G. C., Lewis, G. P., Forest, F., Nyirenda, S. P., Belmain, S. R., Sileshi, G. W., \& Veitch, N. C. (2012). Distinct chemotypes of Tephrosia vogelii and implications for their use in pest control and soil enrichment. Phytochemistry 78, 135-146. 
Philip C. Stevenson is Professor of Plant Chemistry and Head of Chemical Ecology at the University of Greenwich's Natural Resources Institute. He is also Senior Research Leader of Chemical Ecology and In vitro Biology at the Royal Botanic Gardens, Kew. He obtained his PhD from the University of London on natural resistance mechanisms in groundnuts to Lepidopteran pests and continues to study environmentally benign pest control. The main focus of his most recent work has been exploiting plants as pesticides for field crop and stored product pests, targeting small-holder farming in sub-Saharan Africa to improve their livelihoods. He also studies the role of floral chemicals in the health and behaviour of pollinators. His research is published in over 100 journal articles, books and book chapters. He is a Fellow of the Royal Entomological Society, a Subject Editor for the Bulletin of Entomological Research, and is on the Editorial Board of Crop Protection.
Steven R. Belmain is Professor of Ecology at the University of Greenwich's Natural Resources Institute. He obtained his PhD from the University of London on the ecology of the death-watch beetle. His research interests span both vertebrate and invertebrate pests to develop ecologically sustainable methods of pest control and investigating how improvements in ecosystem services can lead to reduced disease within a One Health paradigm. As a field biologist working mainly in Africa and Asia, he has led more than a dozen large multidisciplinary research projects that have resulted in well over 100 publications. $\mathrm{He}$ is a Fellow of the Royal Entomology Society, Fellow of the Higher Education Academy, Coordinating member of the International Society of Zoological Sciences, Committee member of the World Health Organisation's Global Leptospirosis Environmental Action Network and Associate Editor for the journal Wildlife Research.

Similar articles that appeared in Outlooks on Pest Management include - 201021 (4) I56; $201122(5) 211 ; 201425(3) 200$

\section{Future articles in Outlooks on Pest Management will include -}

- Biocontrol of Palmer amaranth with Myrothecium verrucaria

- Peanut pest management

- The work of the James Hutton Institute

- Pesticides and contaminants in surface water related to land use \& evaluation of sampling methods

- The work at CABI

- The President's Malaria Initiative: future of Indoor Residual Spraying for malaria control

- Update on diagnostics and management of mycotoxins

- Botanical pesticides

- Insecticide-treated wall lining for malaria control

- How GM-crops are regulated compared to other crops

- Using traps to control thrips and whiteflies (mass trapping)

- The work of ICIPE

- Aedes albopictus in Holland

- Product stewardship

- Labelling of pesticides and how this relates to pesticide application
- Bt corn root worm resistance

- Seed treatment technology in the UK

- EU maximum residue levels and their impact on imports from less developed nations

- The work of IRAC

- The molecular basis of resistance to SDHI fungicides

Why are there not more GM crops?

- Insecticide discovery in the post-genomic era

- Opportunities for non-food crops in today's farming systems

- Controlling potato cyst nematode in potato crops with a fungus

- Counterfeiting and other illegal PPPs

- Insecticide Toxicology with particular reference to cotton ecosystems

- Economics of insect pathogens used for insect management 